\title{
Estimation of the height by using hand-span; a clinical forensic study
}

Tikiri KMB Gunathilake ${ }^{1 *}, \triangle$ D Sithum M Manjika ${ }^{2}$, Muditha Vidanapathirana ${ }^{3}$, KAP Siddhisena ${ }^{4}$

${ }^{1}$ Office of the Judicial Medical Officer, Base Hospital, Awissawella, Sri Lanka.

${ }^{2}$ Department of Community Medicine, University of Sri Jayewardenepura, Sri Lanka.

${ }^{3}$ Department of Forensic Medicine, University of Sri Jayewardenepura, Sri Lanka,

${ }^{4}$ Department of Demography, University of Colombo, Sri Lanka

\section{Introduction}

For identification of the dead, the assessment of height is important. There is a folk knowledge among sculptors that the height is eight times the hand-span. This research was conducted to assess whether there is a relationship between hand-span and heightin adults.

\section{Methodology}

A cross-sectional study was performed on consented adults attending a provincial hospital. From the hand-span (X) a hypothesis was made. Height $=$ Head $(1 X)+$ Trunk $(3 X)+$ Thigh $(2 X)+\operatorname{Leg}(2 X)=8 X$. Data were collected from 340 participantsand were analyzed using SPSS-19.

\section{Results}

Of the participants $82 \%(\mathrm{n}=279)$ were females. Ages ranged from 18-74 years (mean 28.8 +/- SD 10.099). Heights ranged from 51-72 inches (mean 62.27 +/-SD3.007). The hand-span ranged from 6-9 inches (mean 7.490 +/-SD 0.587). There is a positive high correlation between hand-span and height $(\mathrm{r}=0.651)$ for males whilst a positive moderate correlation $(\mathrm{r}=0.461)$ for females $(\mathrm{p}=0.000)$. In Regression Analysis, though age was not statistically significant for both males $(\mathrm{p}=0.539)$ and females $(\mathrm{p}=0.477)$, the $\mathrm{F}$ value was significant $(\mathrm{p}=0.000)$ and hand-span showed a positive effect on the determination of the height of both males and females even controlling for age. According to Independent Sample T-test, the relationship between means of 'hand-span x 8' with gender had a highly statistically significant association $(t=5.325$, $\mathrm{df}=325$ and $\mathrm{p}=0.000)$ and the mean values for males was 62.78 with $\mathrm{SE}+/-0.51$ inches and for the females, the mean was 59.31 with $\mathrm{SE}+/-0.28$ inches.

\section{Conclusions}

The study formulated the following formula. Person's height=hand-span $\mathrm{x} 8+/-\mathrm{SE}$ inches.Further, according to this study, the probable height of a male in inches $=$ hand-span $x 8+/-0.51$ inches. For the females, the probable height in inches $=$ hand-span $\times 8$ / 0.28 inches. Finally, a national scale research is recommended Keywords: Gender-based violence, Intimate partner violence, Community violence, Sexual violence, Weapons, Sri Lanka.

Copyright: @ 2018 with the Medico-legal Journal of Sri Lanka.

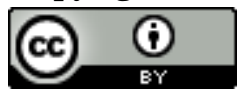

This is an open-access article distributed under the terms of the Creative Commons Attribution 4.0 International License, which permits unrestricted use, distribution and reproduction in any medium provided the original author and source are credited

Funding: None

Competing interests: None

Received:23 June 2018 Accepted revised version:15 December 2018 Published: 30 December 2018

*Corresponding author:Gunathilake KMTB, Email: tikiriii_bandara@yahoo.com,

(iD https://orcid.org/0000-0002-8485-4550

Cite this article as: Gunathilake KMTB, Manjika MS, Vidanapathirana M, Siddhisena KAP. Estimation of the height by using hand-span; a clinical forensic study.Medico-Legal Journal of Sri Lanka, 2018; 6(2):64-69.

DOI: http://dx.doi.org/10.4038/mljsl.v6i2.7376 


\section{Introduction}

Though there are many differences within human species, there are many common features among them. Forexample, in whole human species there are only four major blood groups; $\mathrm{A}, \mathrm{B}, \mathrm{AB}$, and $\mathrm{O}$. Similarly, there are many common body proportions with limitations among a species that decided by nature.

The height ofthe world population fallsbetween 1 foot $3 \frac{1}{2}$ inches and 8 feet and 3 inches. ${ }^{[1]}$ Although these are extremes, in some countries, people are generally tall (USA 5' 9', Australia 5' 9', Canada 5'.9) and in some countries, people are short (China5' 5",Sri Lanka5' 4.5",Peru5' 4.5"etc). ${ }^{[2]}$ Even though it is believed that genetic and environmental factors play major roles, it is generally obvious that nature had given certain biological limitations and common features to a human being. There are certain body proportions which can be used to calculate body measures.In elephants, height could be calculated by multiplying circumference of the foot into six times. ${ }^{[3]}$ In forensic anthropology, there are a lot of calculations using the measurementsof bones. The followingresearch is based on the estimation of body stature by using the biological comparative method and to apply these values in practical forensic investigations.

There is a folk knowledge in sculpting that the body proportions of human should have universal relationships. For example, there is a belief that the stature is eight times the hand-span. To test this, the length of the hand-span was used as a unit to assess the stature of the body. Therefore, the following hypothesis was made as shown in the diagram.

The identification of a dead is an essential part of a post-mortem examination. Some of the important issues includeethical and humanitarian need to identify who has died. ${ }^{[5]}$ Specially for relatives, Official, statistical and legal purposes, administrative and ceremonial purposes in respect of burial or cremation, legal claims and obligations in relation to property, estate and debts, claims of life insuranceand financial matters, to allow legal investigations and other tribunals, such as inquirers, coroners, medicalexaminers, judges to proceed with investigations, and to facilitate police inquiries to investigate criminal or suspicious deaths, the ascertainment of the identity of deadis important. ${ }^{[5]}$

By testing the above hypothesis, if a positive relationship is established, it is possible to reconstructthe stature of a person without using complex calculations and expensive investigations.

This research was conducted to see whether there is a relationship between hand-span (X) and stature, whether is it possible to apply this principle to both males and females equally and to see whether these body proportions change with age. The main objectiveof this research was to develop a system to formulatestature of the body by using the handspanand to apply in practical forensic investigations. For example, assessment of the stature of unidentified persons by using body parts with soft tissues, dismembered hands, prints of the stretched handetc.

\section{Methodology}

Across-sectional study was performed at a Provincial General Hospitaland the correlations between height and hand-spanwere assessed. The study population was the consented adult volunteers those who were attending the hospital. Both males and females were considered. The children, persons with deformities, persons with disease conditions which could affect height such as spinal cord problems, persons with congenital body abnormalities, hormonal and metabolic conditions which could affect the height were excluded.

A convenient sample was selected and subjected to the inclusion and exclusion criteria. Data were collectedfrom 340 participants using a data collection form. Age, sex, and anthropometric measurements (hand-span and height) were taken by Medical officerswho work in the office of the Judicial Medical Officer. The Medical officers who obtained the measurements were given prior training. Stadiometer was used to assess the fully erect height (Fig. 01). Right-Hand-spanwas taken after stretching the little finger and thumbas much as possible touching the surface and in a straight line (Fig. 02). A vertical piece of sheet was used to mark the tips of the fingers. Two measurements were taken 3 minutes apart from each other and the average was taken.

From the hand-span $(\mathrm{X})$ a hypothesis was made. Height $=$ Head $(1 X)+$ Trunk $(3 X)+$ Thigh $(2 X)+$ Leg $(2 X)=8 X($ Fig. 03 and 04) 


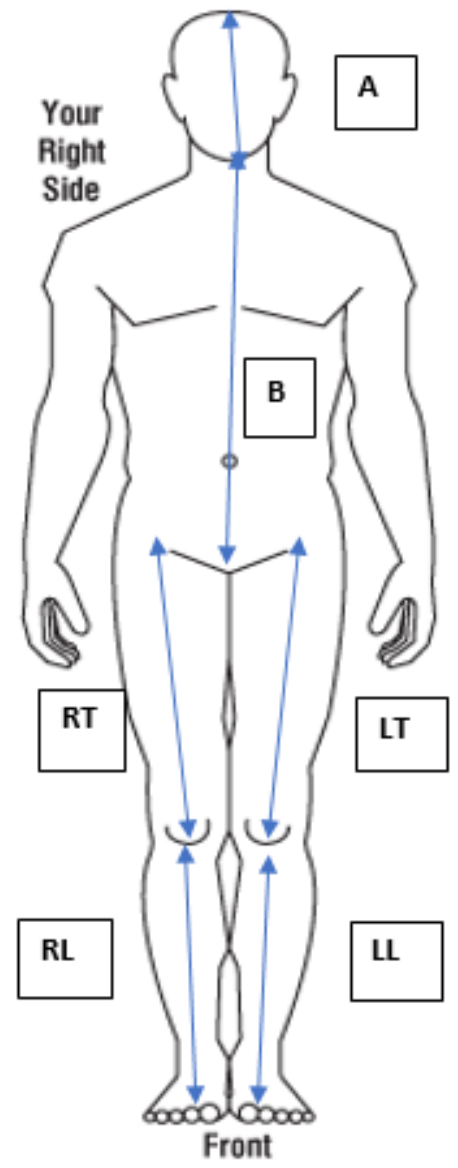

Figure 01: Height $=$ Head + Trunk + Thigh + Leg

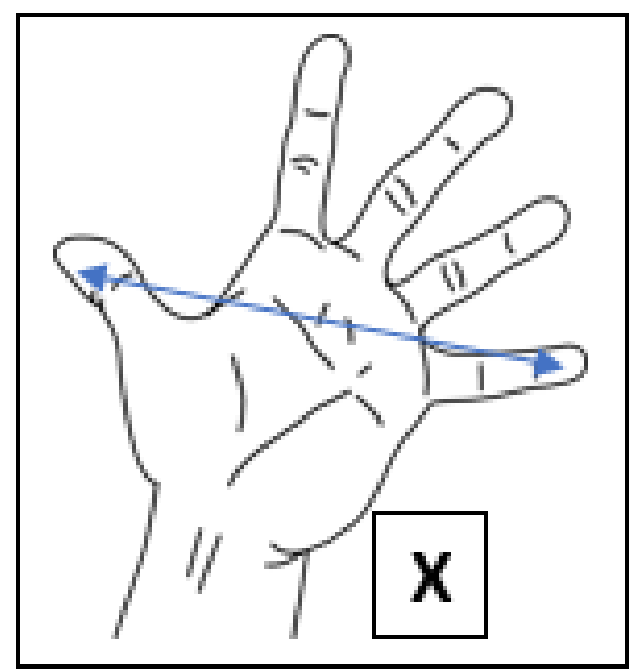

Figure 02: If the length of handspan $=\mathrm{X}$ inches

\begin{tabular}{|l|l|}
\hline$A$ & $=X$ (inches) \\
\hline$B$ & $=3 X$ \\
\hline$U R, U L$ & $=3 X$ \\
\hline$T R, T L$ & $=2 X$ \\
\hline LR, LL & $=2 X$ \\
\hline Total Height & $=8 X$ inches \\
\hline
\end{tabular}

Figure 03: Height according to hand-spans

$$
\begin{aligned}
& \text { Height }=\mathrm{A}(1 \mathrm{X})+\mathrm{B}(3 \mathrm{X})+ \\
& \text { Thigh }(2 \mathrm{X})+\operatorname{Leg}(2 \mathrm{X})=8 \mathrm{X}
\end{aligned}
$$

Figure 04: Hypothesis of Height

Anonymous data were analyzed using IBM-SPSS 19 software. Pearson correlation coefficient ( $r$ ) was used to measure the correlation between height and handspan. Regression was used to quantify the relationship between height and hand-span. The Ttest was used to compare the mean values. Ethical clearance was obtained from the Ethics Review Committee, PGIM, Colombo.

\section{Results}

There were 340 participants. Out of them, $18 \%(n=61)$ were males and the remaining $82 \%(\mathrm{n}=279)$ were females.

The ages ranged from $18-74$ years (mean $28.8+/-$ SD 10.099$)$ and $75 \%(n=257)$ belonged to $18-29$ age group. The age distribution is seen in Table 01 . 
Table 01: The distribution of age

\begin{tabular}{lr}
\hline \hline Age ranges & $\begin{array}{r}\mathbf{N}=340 \\
\mathbf{n}(\%)\end{array}$ \\
\hline $18-29$ & $257(75)$ \\
$30-39$ & $43(12)$ \\
$40-49$ & $19(06)$ \\
$50-59$ & $13(04)$ \\
$60-69$ & $06(02)$ \\
$70-79$ & $02(01)$ \\
\hline \hline
\end{tabular}

The heights ranged from 51 to 72 inches (mean 62.27 +/-SD 3.007) and 81\% (n=277) were 60.00- 69.99 inches in height. The distribution of the height is shown in Table 02.

Table 02: Distribution of the heights

\begin{tabular}{lr}
\hline \hline Height ranges (inches) & $\begin{array}{r}\mathbf{N}=\mathbf{3 4 0} \\
\mathbf{n}(\boldsymbol{\%})\end{array}$ \\
\hline $50.00-59.99$ & $56(17)$ \\
$60.00-69.99$ & $277(81)$ \\
$70.00-79.99$ & $07(02)$ \\
\hline \hline
\end{tabular}

The lengths of the hand-span ranged from 6 to 9 inches(mean 7.490 +/-SD 0.587) and the 7.00-7.99 inches were $58 \%(\mathrm{n}=198)$. The distribution of the hand-spans is shown in Table 03.

Table 03: Distribution of the hand-spans

\begin{tabular}{lr}
\hline \hline Hand-span ranges (inches) & $\begin{array}{r}\mathbf{N = 3 4 0} \\
\mathbf{n}(\%)\end{array}$ \\
\hline $6.00-6.99$ & $24(07)$ \\
$7.00-7.99$ & $198(58)$ \\
$8.00-8.99$ & $109(32)$ \\
$9.00-9.99$ & $09(03)$ \\
\hline \hline
\end{tabular}

When the whole sample (both males and females) was considered, the hand-span and the height showed a positive moderate correlation $(\mathrm{r}=0.546)$ with statically significant $(\mathrm{p}=0.000)$. When the scatter plot was used to examine the relationship between handspan and height, there was a positive correlation $(\mathrm{r}=0.546)$ and the relationship was significant at $99 \%$ confidence level ( $\mathrm{p}=0.000$ ) (Fig. 05).

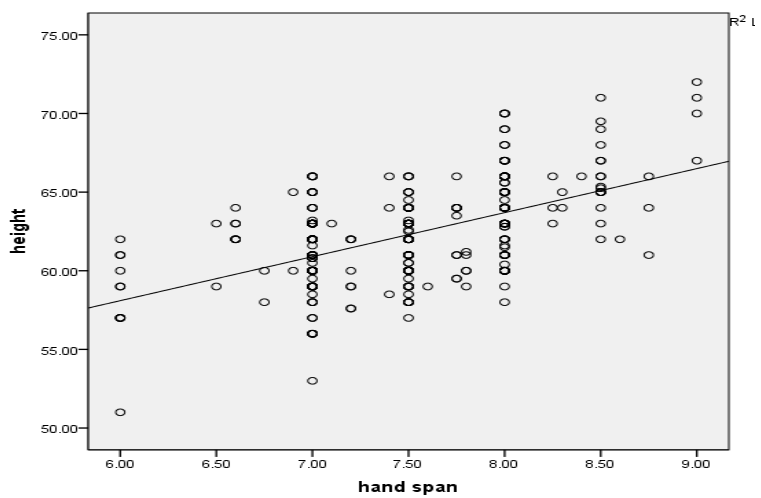

Figure US: Scatterplotgraph of the whole sample with the fit line.

When the males were considered separately, there was a positive high correlation between hand-span and height $(\mathrm{r}=0.651)$ with statistical significance $(\mathrm{p}=0.000)($ Fig. 06)

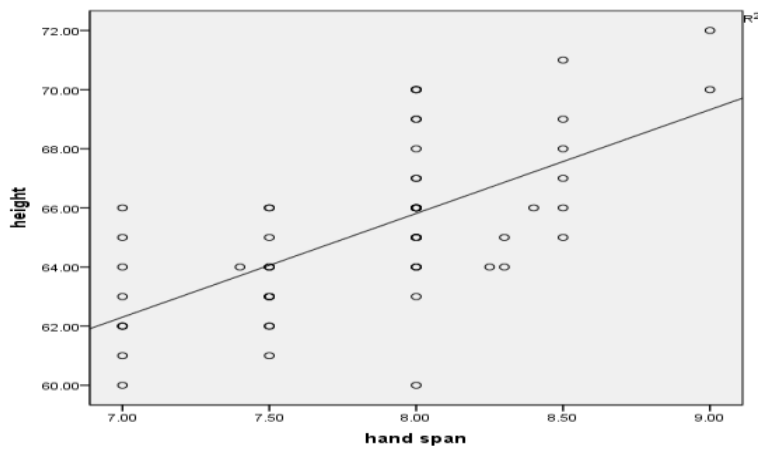

Figure 06: Scatterplot graph of the male sample with fit line.

We had to decide whether the hand-span affects the determination of the height of a male. In order to test the relationship, we performed linear regression in taking the height as the dependent variable and the age and hand-span as independent variables. According to the full model ( $F$ value) was significant $(\mathrm{p}=0.000)$ and independent variable we entered the model (hand-span) was significant at a 99\% confidence level. However, age was not statistically significant $(\mathrm{p}=0.539)$. It is interesting to note that hand-span had a positive effect on the determination of the height of male and it is significant at $99 \%$ even controlling for age.

When the females were considered separately, there was a positive moderate correlation between handspan and height $(r=0.461)$ with statistical significance $(\mathrm{p}=0.000)$ significance (Fig. 07). 


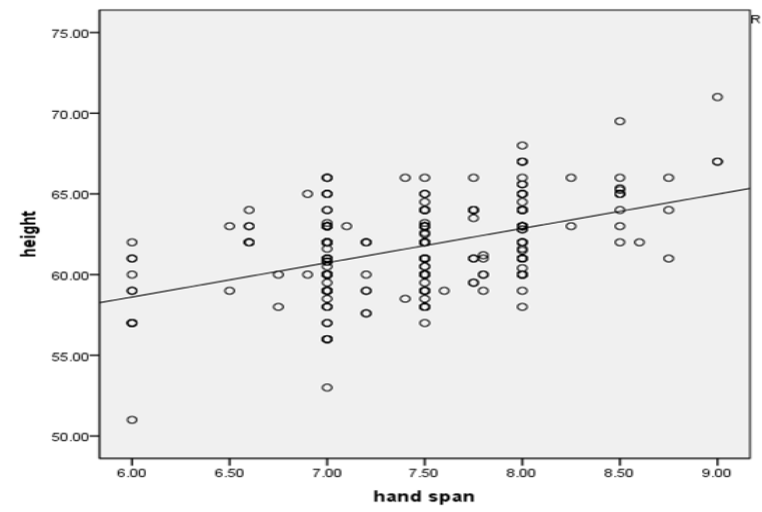

Figure 07: Scatterplot graph of the female sample with the fit line.

We had to decide whether hand-span affects the determination of the height of a female. In order to test the relationship, we performed linear regression in taking the height as the dependent variable and the age and hand-span as independent variables. According to the full model ( $\mathrm{F}$ value) was significant $(\mathrm{p}=0.000)$ and independent variable we entered the model (hand-span) is significant at a $99 \%$ confidence level. However, the age wan not statistically significant $(p=0.477)$ for females as well. It is interesting to note that hand-span has a positive effect on the determination of the height of a female and it is significant at $99 \%$ even controlling for age.

In order to assess the relationship between means of height and hand-span $\times 8$, we used the independent sample T-test. According to Independent Sample Ttest, the relationship between means of 'hand-span $\mathrm{x}$ 8 ' with gender had a highly statistically significant association $(\mathrm{t}=5.325, \mathrm{df}=325$ and $\mathrm{p}=0.000)$.

According to the results for the males, the mean was 62.78 with SE +/- 0.51 inches and for the females, the mean was 59.31 with $\mathrm{SE}+/-0.28$ inches.

\section{Discussion}

The main focus of the paper was whether the measurement of hand-span determinesthe height of a person.

Further, calculations of the height may be possible without using population comparative data. It is very important to know the height of a person for tentative or general identification which is an initial step of positive identification. Identification of a person is one of the most important factors in forensic investigations. ${ }^{[5]}$ There are many method and calculations available for stature assessment by using skeletons and bones but very few in body parts with soft tissues. The application of the findings in this study is mainly with the body or dismembered parts of the body. Eg: hand. To apply the results, comparative databases are not necessary. Calculations are simple and can be done within a short period.

In forensic investigations based on body parts, such as following bomb blasts, aviation accidents, landslides, building collapse, murder and mutilated and dismembered bodies, road trauma and train accidents etc.in such situations it is possible to reconstruct the stature by using remaining body parts.

Limitations are the persons with hand or spine deformity or conditions which affect the length of hand-span such as cretins, children, extremes of age, dwarfs etc. ${ }^{[6]}$

In the practice of forensic pathology, there are many situations where the estimation of stature is important. However, in practice, there are few methods available to estimate height by using body parts. The method discussed here is, non-invasive, time saving, easily applicable, no need of complex calculations, even with small body part such as hand can be used to reconstruct total stature of a person, no need of other expertise involvement, no need of expensive investigations such as $\mathrm{x}$-rays, and even handprint can be used. These findings can be used to introduce an easy method of assessing stature of a person, which can be used to resolve important medicolegal issues which are forensically important.

It appears that the weight of a person does not affect the determination of the height of adults. Same height people can have different weight measurements. Therefore, it was not considered in this paper.

\section{Conclusions}

Finally, this study found that the person's height very similar to their hand-span x $8+/-$ SE. According to this study, we can formulate the following formula to measure the height of a person using theirhand-span.

\section{Person's height $=$ Hand-span $\times 8+/-$ SE}

Further, according to this study, the probable height of a male in inches $=$ hand-span $\times 8+/$ - 0.51 inches. For the females, the probable height in inches = hand-span $\times 8+/-0.28$ inches. Finally, national scale research is recommended.

\section{References}


1. Tallest and shortest man. Available from www.cnn.com/2014/11/13/living/tallest-shortestman-guinnes.cited on 11.10.2017

2. Average male height by country. Available from http://www.average height.co/average-maleheight-by-country.Cited on 10.10.2017.

3. Wijesekera J. Human evolution symbols in Ratnapura. Sarasavi publishers: Colombo; 2014. ISBN-978-955-31-0228-7

4. ShepherdR. Simpson's Forensic Medicine. $12^{\text {th }}$ ed. Arnold: London; 2003. p49. ISBN-0- 340 76422-8

5. Knight's B. Knight's Forensic Pathology. $3^{\text {rd }}$ ed. Arnold: London; 2004. p98. ISBN0- 340-760443

6. Congenital hand differences. Available from https://my.clevelandclinic.org/health/ articles/congenital-hand. Citedon 11.10.2017. 